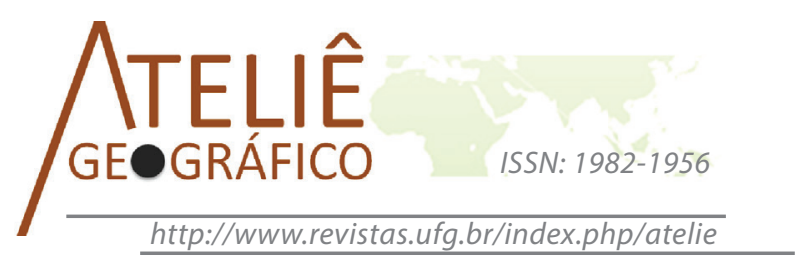

\title{
Análise da temperatura e umidade relativa do ar em episódio de inverno na cidade de Assis/SP
}

\author{
Analysis of temperature and humidity on air in winter \\ episode in Assis/SP
}

\section{Análisis de temperatura y humedad relativa en el aire en episodio de invierno en Assis/SP}

\author{
Rafael Gotardi Brússolo \\ Universidade de São Paulo \\ rgbrusolo@usp.br
}

\begin{abstract}
Resumo
$\mathrm{O}$ ambiente urbano modifica o balanço de energia entre a superfície e a atmosfera, provocando alterações no clima em uma escala local. Dessa forma, esta pesquisa foca o município de Assis, localizado no oeste do Estado de São Paulo. O principal objetivo deste trabalho foi averiguar as características da temperatura e umidade do ar em ambientes com usos e ocupações dos solos diferenciados, no inverno, no período noturno, sendo um inserido na malha urbana de Assis, outro na periferia da cidade, e o outro no ambiente rural, a fim de verificar se há indícios de mudanças nos elementos climáticos causados pela urbanização. Para a coleta de dados foram utilizadas miniestações meteorológicas automáticas que registram dados de temperatura e umidade do ar. Para análise dos resultados foram realizadas comparações entre os dados obtidos na cidade e no campo, elaborando gráficos utilizando o aplicativo EXCEL a fim de tabular os dados. Constatou-se que houve diferenças termo-higrométricas entre os pontos de coleta de dados, evidenciando um clima urbano específico no município de Assis.
\end{abstract}

Palavras-chave: Assis. Clima Urbano. Qualidade Ambiental Urbana.

\begin{abstract}
The urban environment modifies the energy balance between the surface and the atmosphere, causing changes in the climate on a local scale. Thus, the present study focused on the municipality of Assis, located in the western region of the State of São Paulo, and its primary objective was to determine the characteristics regarding temperature and air humidity in environments with different land use and
\end{abstract}


occupation, during the winter, at night. The environments consisted of: the urban area of Assis, the outskirts of the city, and its rural area; and evidence of changes in climatic elements due to urbanization was verified. Data collection was carried out employing mini automatic weather stations that record information on temperature and humidity. Result analysis was carried out by comparing the data obtained in the city and the countryside, with the development of graphs using Excel to tabulate the information. Differences were observed with respect to the thermo-hygrometric data collection points, revealing a particular urban climate in the city of Assis.

Keywords: Assis. Urban climate. Urban environmental quality.

\begin{abstract}
Resumen
El ambiente urbano es capaz de modificar el balance de energía entre una superficie y la atmósfera, provocando cambios a escala local en el clima de las ciudades. Este trabajo fue realizado en el municipio de Assis, ubicado al Oeste del Estado de São Paulo. El objetivo de estudio fue evaluar las características de la temperatura y humedad en diferentes ambientes considerando uso y ocupación de suelos, durante periodos nocturnos de invierno. De este modo, fue considerado uno de los emplazamientos dentro de tejido urbano de Assis, otro a las afueras de esta ciudad y otro en zona rural, con el fin de verificar si existen evidencias de cambios en los elementos climáticos causadopor la urbanización. Para el registro de los datos de temperatura y humedad se utilizaron estaciones meteorológicas automáticas y para el análisis de los resultados, se realizó una comparación de los datos obtenidos en la ciudad con los de zona rural. Para el desarrollo de los gráficos y tabulación de los datos, fue utilizado el programa EXCEL. De este trabajo se concluyeron diferencias termo-higrométricas de los datos entre los puntos de registro, lo que constata un clima urbano específico en la ciudad de Assis.
\end{abstract}

Palabras clave: Assis. Clima Urbano. Calidad Ambiental Urbana.

\title{
Introdução
}

Com a Revolução Industrial, a cidade se tornou foco de atração populacional, devido à facilidade de trocas de bens, serviços, informações, etc. Esse fato associado ao fluxo constante de pessoas oriundas do ambiente rural para as cidades propiciou o superpovoamento destas. O ambiente urbano se tornou sinônimo de industrialização, contingente populacional e logística para atender as necessidades do modo de vida capitalista. A modificação da paisagem natural pela paisagem antrópica não ocorreu de maneira harmônica. Sant'Anna Neto (1995, p.30) afirma "como este ambiente é vivo e regulado por processos e dinâmicas próprias, responde às alterações impostas pelo homem, resultando em níveis de derivações dos sistemas, naturais e antrópicos, dos mais variado".

O meio natural é substituído pelas áreas construídas, pela pavimentação asfáltica, pelo adensamento populacional etc. Essa remoção da cobertura natural, e a formulação do sítio urbano, aliado as intensas atividades socioeconômicas, proporcionam mudanças no balanço de energia entre a superfície e a atmosfera, afetando o regime hídrico das precipitações pluviais, aumento da temperatura, queda da qualidade do ar, entre outros. (BRANDÃO, 1996, p.85). 
Essa alteração no sistema, devido às interferências humanas, acaba resultando na produção de fenômenos como a ilha de calor, a inversão térmica, agravamento do efeito estufa, dentre outros. Além disso, provoca alterações na circulação secundária da atmosfera, causando irregularidades das chuvas.

Embora a expressão territorial das cidades de porte médio, como é o caso de Assis, não se compare com as de grande porte, é necessário estudos para averiguar o potencial de alterações que esta área urbanizada pode provocar na atmosfera na escala local. Acrescentando que, as populações devem de maneira igualitária usufruir de organização espacial bem planejada e de qualidade ambiental urbana adequada.

A área rural é utilizada como comparação entre a temperatura e umidade relativa do ar, por não apresentar as mesmas características de uso e ocupação do solo urbano. Trata-se então de uma maneira de demonstrar o quanto as cidades interferem nas condições climáticas locais. Sendo assim, contribui de maneira importante para a constatação do clima urbano. Com base nisso, este estudo poderá contribuir para pesquisas de clima urbano com uma abordagem geográfica.

Os estudos relacionados com a modificação dos elementos climáticos na área urbana, originando o clima urbano, tiveram início no século XIX, sendo um dos trabalhos precursores o realizado por Howard em 1833, onde ele analisou as características da ilha de calor em uma cidade de clima temperado (AMORIM, 2000).

A exploração do sítio urbano pelas atividades socioeconômicas e o uso e ocupação do solo desordenado gera mudanças no balanço energético, alterando, por exemplo, o albedo, devido à utilização de materiais que modificam a paisagem natural, causando alterações entre o que entra (input) e o que sai (output) de energia na superfície. Isso gera o fenômeno ilha de calor. Alguns estudiosos demonstraram as principais causas deste acontecimento: Chandler, 1965; Oke, 1978; Lombardo, 1985; Monteiro, 1976,1990; Mendonça, 1994; Brandão, 1996, Amorim (2000), entre outros.

No Brasil os estudos referentes à climatologia urbana iniciam-se em meados da década de 1970. Monteiro (1976 e 1990) realizou uma abordagem teórico-metodológica acerca do clima urbano, associado ao espaço geográfico, embasado numa perspectiva sistêmica.

A maioria dos estudos iniciais focava cidades de porte grande, como as metrópoles. Neste sentido "As metrópoles são o melhor exemplo de deteriorização da qualidade ambiental, pois, há muito tempo, o tamanho da mancha urbana tornou-se inconveniente à sustentação de um conforto térmico mínimo à população" (ARAÚJO, p. 10, 2001).

Apesar dos estudos direcionados ao clima urbano nas cidades brasileiras serem muito recentes, observa-se um crescimento/adensamento dos trabalhos, porém ainda muito inferior ao ideal. Ressaltam-se alguns trabalhos como de Pitton (1997), onde a autora analisa as condições térmicas das cidades de Rio Claro, Araras, sendo essas caracterizadas como cidade de porte médio, e Cordeirópolis e Santa Gertrudes, classificadas como de porte pequeno. Realizaram-se as pesquisas em duas estações distintas (inverno e verão), concluindo que as anomalias térmicas relacionadas às 
cidades ocorrem por sua categoria dimensional, sugerindo a adoção de áreas verdes para amenização dos problemas relacionados ao campo térmico. Sampaio (1981) visou sistematizar metodologicamente um percurso que possibilitasse correlacionar como variáveis o uso do solo e a ilha de calor para o caso de Salvador. O autor observou que a magnitude de uso e ocupação do solo não corresponderia linearmente com a alteração da temperatura. Mesmo assim conseguiu identificar contrastes entre áreas livres e edificadas, no que tange as temperaturas máximas e médias. Este trabalho demonstra o problema de tornar independente a variável uso do solo na constatação da ilha de calor.

Em se tratando da ilha de calor, Lombardo (1985) estudou a ilha de calor nas metrópoles, dando destaque para a capital paulista. Relacionou a qualidade ambiental, uso do solo e ilha de calor. Em escala inferior, Fonzar (1981), estudou a ilha de calor em Presidente Prudente-SP.

Sartori (1979) estudou as consequências do fenômeno ilha de calor na cidade de Santa Maria, no Rio Grande do Sul, sendo essa cidade considerada de porte médio. É considerada uma das primeiras geógrafas a utilizar o Sistema Clima Urbano (SCU) proposto por Monteiro, 1976.

Danni (1987) estudou a espacialização das ilhas de calor na cidade de Porto Alegre, verificando o aparecimento do fenômeno em áreas densamente edificadas e industrializadas. Constatou-se o aparecimento das ilhas frias sobre as regiões periféricas, devido as características do uso e ocupação do solo diferenciadas.

Zamparoni (1995), estudando as cidades de Barra do Garça e Tangará da Serra, no estado do Mato Grosso, relacionou o aquecimento destas à retirada da vegetação e o crescimento do asfaltamento e cimentação das ruas e avenidas.

Sette (1996), realizou um estudo de caso na cidade de Rondonópolis, Mato Grosso.Utilizou a temperatura e umidade relativa do ar, adicionando a temperatura do solo e a precipitação.

Tomás (1999) analisou o comportamento da umidade relativa do ar na cidade de São Paulo.

Amorim (2000) analisou o clima urbano de Presidente Prudente -SP, dando destaque para o campo termodinâmico. A autora ressalta a importância do uso e ocupação do solo, a presença ou não de vegetação, altitude e a exposição das vertentes, para a caracterização de um clima urbano específico.

Araújo (2001) estudou a produção do clima urbano em São Luis - MA. Analisou a temperatura e umidade relativa do ar, a fim de diagnosticar possíveis alterações desses elementos, levando-se em consideração o uso do solo urbano (área de verticalização urbana, adensamento e concentração horizontal e áreas de significativa cobertura vegetal).

Souza (2007) analisou o campo térmico das cidades de Americana, Nova Odessa, Santa Bárbara D'Oeste e Sumaré. Constatou com a pesquisa que as mudanças no clima local ocasionadas pelo modo de vida urbano, podem ser reversíveis em uma escala de tempo reduzida, dependendo das ações políticas visando melhorias na qualidade ambiental urbana. 
A remoção da cobertura vegetal, a canalização das superfícies líquidas acompanhado da escassez de áreas verdes, propicia a redução do fluxo de calor latente e aumento do calor sensível, o que diminui a umidade e a evaporação. As novas rugosidades (edifícios) formam verdadeiros canyons urbanos, resultando em menores perdas de radiação de ondas longas, e contribuem também para o agravamento do fenômeno ilha de calor. Brandão (1996) afirma que a ilha de calor representa a ação mais efetiva do clima urbano e sua intensidade depende das condições micro e mesoclimáticas locais de cada cidade. Além do desconforto térmico, a péssima qualidade do ar e as chuvas concentradas ocasionando as inundações, são outros agravamentos gerados pelo modo de vida urbano. O fluxo constante de veículos e a densidade industrial aumentam a concentração de poluentes na cidade, o que provoca doenças respiratórias, circulatórias, etc., e, contribuem para o fortalecimento das chuvas localizadas, porque esses poluentes em suspensão na atmosfera servem de núcleo de condensação para o vapor de água. Esse fato, adicionando a (des)organização urbana, contribuem para problemas de inundações, escorregamentos e desmoronamento de encostas etc. (GONÇALVES, 1992).

Este trabalho possibilitará o entendimento das anomalias termo-higrométricas entre o ambiente urbano e rural do município de Assis, em episódio de inverno no período noturno, e poderá ajudar na análise das relações cidade-campo através das observações meteorológicas básicas para a interpretação da geração do clima da cidade. Esperase que este estudo contribua para o planejamento urbano, e consequentemente para a melhoria na qualidade de vida urbana, visando o bem-estar da população. Pretendese também contribuir para os estudos do clima das cidades do oeste paulista, tanto de pequeno ou médio porte, procurando dar subsídios para a orientação territorial urbana, e também para estimular a comunidade científica para essa temática, visto que há carência de estudos nessa área.

O município de Assis localiza-se no oeste do Estado de São Paulo (Figura 1). Está a uma altitude de 546 metros acima do nível do mar. É sede da Região de governo do Estado e do Consórcio Intermunicipal Vale do Paranapanema, o CIVAP, que agrupa 21 municípios, somando aproximadamente 400 mil habitantes.

Possui população em torno de 95 mil habitantes (IBGE, 2010), sendo 4000 vivendo na área rural. Ocupa área de $462 \mathrm{Km}^{2}$ e se distância $430 \mathrm{~km}$ da capital paulista.

Assis é privilegiada por apresentar grande quantidade de rios que enriquecem o solo e garantem o abastecimento para a agricultura, principalmente de soja, trigo, milho e cana-de-açúcar. Destacam-se o Rio Cervo, Jacu, Pavão, Capivara, Palmitalzinho, Fortuna e Matão, pertencentes à bacia hidrográfica do Médio Paranapanema- Rio Paranapanema. Os córregos que atravessam a cidade (Fortuninha e Jacu) já sofreram muitas mudanças no que tange à largura, à profundidade, à vazão e à vegetação ribeirinha.

A cidade está localizada na região intertropical, e devido a latitude que se localiza as chuvas estão concentradas predominantemente no verão, de dezembro a março, e o inverno caracteriza-se pelo clima seco. Porém pode haver mudanças no balanço térmico e hídrico sazonal, em circunstâncias de eventos climáticos globais ou regionais, como $\mathrm{El}$ Nino e La Nina, por exemplo. 


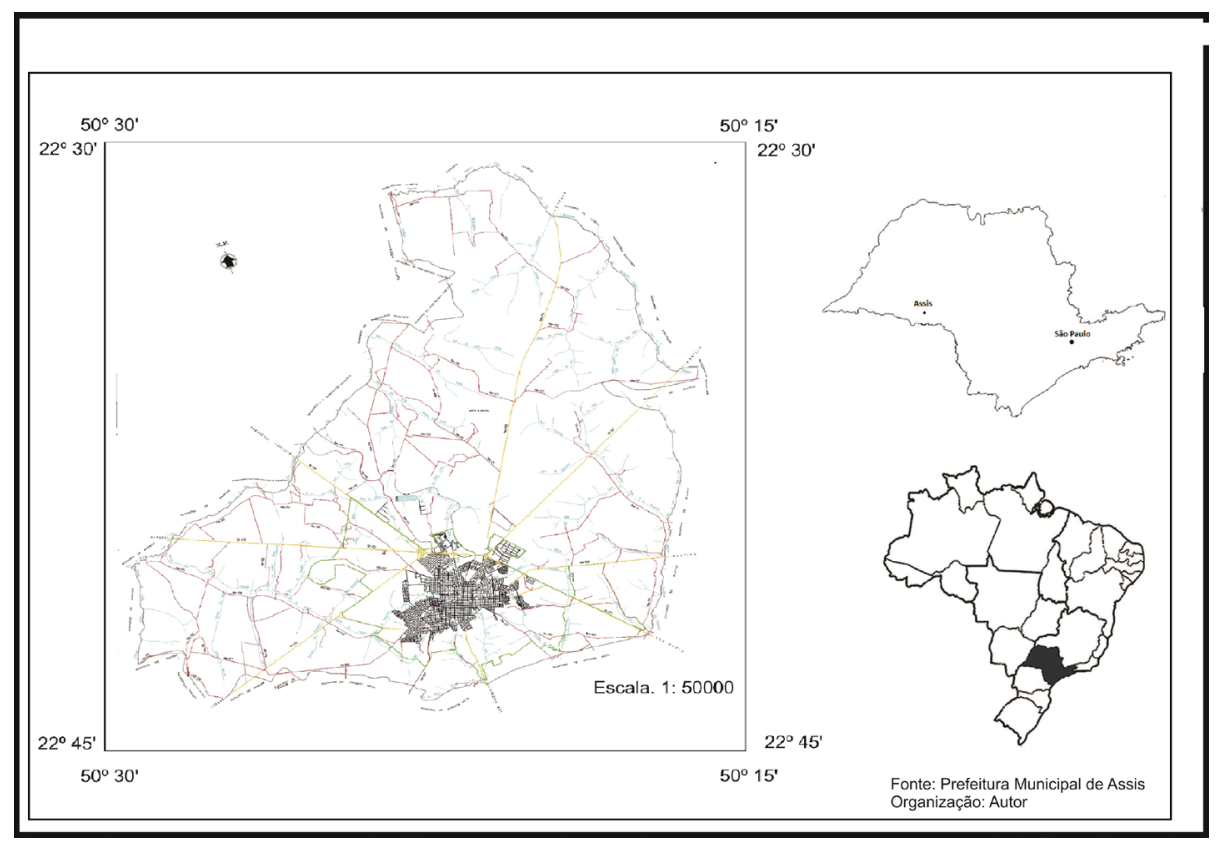

Figura 1. Localização do município de Assis/SP

A vegetação se diversifica em campo, cerrados e uma pequena parcela de Mata Tropical. Cabe salientar que devido a expansão do agronegócio na região, principalmente da cana-de-açúcar, grande parte da vegetação original foi derrubada. O relevo é caracterizado como Planalto Ondulado Suave.

As atividades econômicas do município estão baseadas na pecuária de corte e no cultivo de soja, trigo, milho e cana-de-açúcar, além de comércio forte que atrai compradores de toda região e pequeno parque industrial com destaque para as empresas de concreto. Nota-se também o setor de serviços muito forte, que representa uma grande parcela do produto interno bruto (PIB), e um potencial turístico na região do Médio Paranapanema.

\section{Materiais e método}

Para a realização deste estudo, foram realizadas leituras, fichamentos e discussões a respeito da dinâmica atmosférica regional, o tema clima urbano e ao desenvolvimento e evolução do uso e ocupação do solo na cidade de Assis. is ișpị Esta etapa do trabalho foi desenvolvida tendo como base o método hipotético-dedutivo, calcado nas proposições metodológicas apresentadas por Monteiro (1976 e 1990). Este autor propôs a terminologia Sistema Clima Urbano (S.C.U) para o entendimento da organização climática da cidade. Para análise e compreensão do S.C.U, este autor propôs a utilização de três subsistemas: o termodinâmico (referente ao conforto térmico), o físico-químico 
(qualidade do ar) e o meteoros de impacto (formas meteóricas, hídricas, mecânicas e elétricas), que interferem na dinâmica socioeconômica urbana. Segundo o próprio autor o clima urbano pode ser compreendido como "um sistema que abrange o clima de um dado espaço terrestre e sua urbanização” (MONTEIRO, 1976, p.95).

Nesse sentido, essa pesquisa é embasada na perspectiva sistêmica, e analisado a partir dos canais de percepção humana.

Esta pesquisa enfatizou o subsistema termodinâmico a partir do estudo das características da temperatura e umidade relativa do ar entre a cidade e o campo.

Os três pontos para as coletas dos dados foram escolhidos de acordo com o uso e ocupação do solo, sendo assim denominados de: Ponto "Periferia", que apresenta baixa densidade de construções, terrenos baldios, etc.; Ponto "Centro", apresentando quantidade significativa de material antropogênico (pavimentação, casas, carros,) e Ponto "Rural", verificado por rarefação em relação às características urbanas, a fim de analisar características como: uso e ocupação do solo, densidade de construções, fluxo de pessoas e veículos, arborização etc. A Figura 2 ilustra a espacialização dos pontos de coleta dos dados de temperatura e umidade relativa do ar.

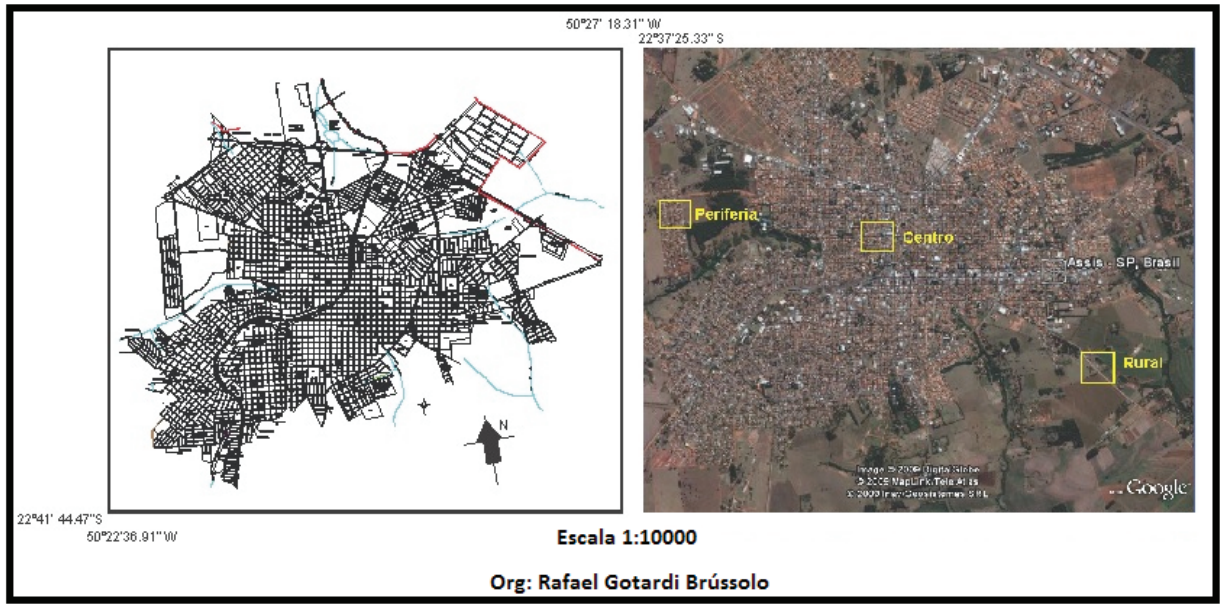

Figura 2. Localização dos pontos de coleta dos dados: "Periferia", "Centro" e "Rural". Fonte: Google Earth/Setembro 2009.

Elaboraram-se gráficos e tabelas a partir da planilha eletrônica EXCEL, que contribuíram para a organização dos cálculos quantitativos.

Para os registros de temperatura e umidade relativa do ar foram utilizadas miniestações meteorológicas automáticas, compostas por uma estação interna e outra externa. As miniestações foram adquiridas com verba do Edital Universal - MCT/CNPq 02/2006. Com essas miniestações foram coletados dados de temperatura e umidade relativa do ar durante 38 dias de duas em duas horas, abrangendo os meses de julho e 
agosto de 2009. Inicialmente os dados seriam coletados somente no mês de julho, porém problemas com as miniestações impossibilitaram os registros de alguns dias, sendo assim foi expandida a coleta dos dados para a primeira semana de agosto. Os dados de superfície foram coletados na Nova América S.A. - Agrícola (Fazenda Nova América - Bairro Água da Aldeia, s/no - Tarumã - SP), e no INMET/Estação: Rancharia-A718, fornecendo subsídios, junto com a bibliografia utilizada, visando entender se as condições atmosféricas foram típicas ou atípicas.

Com os dados coletados foram elaborados gráficos de temperatura e umidade relativa do ar, com o auxílio do software EXCEL, com o intuito de preparar a tabulação estatística dos dados para a análise.

\section{Resultados e discussões}

Para a análise dos sistemas atmosféricos atuantes na região de Assis foram utilizadas as imagens do satélite GOES e informações do Centro de Pesquisas e Estudos Climáticos (CPTEC/INPE) e das Cartas Sinóticas de Superfície da Marinha Mercante do Brasil. Os dados de temperatura, direção e velocidade do vento e pressão, foram fornecidos pelo INMET/Rancharia - A718. Já os dados de precipitação foram fornecidos pela Nova América S.A. - Agrícola (Fazenda Nova América - Bairro Água da Aldeia, s/ $\mathrm{n}^{\mathrm{o}}$ - Tarumã - SP).

No dia primeiro de julho atuou a massa Polar. Durante o inverno, esta massa proporciona, de maneira geral, estabilidade no tempo. A pressão atmosférica ficou em torno de $968 \mathrm{hPa}$. A temperatura máxima registrada foi de $29,4^{\circ} \mathrm{C}$ e a mínima de $14,2^{\circ} \mathrm{C}$, fornecendo uma amplitude térmica de $15,2^{\circ} \mathrm{C}$. Os ventos variaram de NW/SE.

No segundo dia ocorreu a atuação do Complexo Convectivo de Mesoescala (CCM). Esse sistema origina-se na Depressão do Chaco e exerce influência principalmente no oeste paulista. Os centros de baixa pressão sob o continente contribuem para a entrada desse sistema. O que se destaca é o deslocamento da banda de nebulosidade no sentido $\mathrm{SW} / \mathrm{NE}$, a precipitação $(20,32 \mathrm{~mm})$ e os ventos oscilando em torno de $1,1 \mathrm{~m} / \mathrm{s}$.

Nos dias 3 e 4 constatou-se a ação da massa Polar atlântica (mPa). O sistema frontológico não atuou no continente, porém proporcionou a entrada da polar resultou em temperaturas reduzidas (mínima de $15,1^{\circ} \mathrm{C}$ no dia 3 e $11,6^{\circ} \mathrm{C}$ no dia 4). Os ventos foram predominantes do quadrante SE e não chegaram a $2,0 \mathrm{~m} / \mathrm{s}$. Não ocorreu precipitação, porém a precipitação verificada no dia anterior proporcionou altas taxas de umidade relativa.

No dia 5 houve precipitação de $12,66 \mathrm{~mm}$ no período das $7 \mathrm{~h}$, não havendo mais chuvas no restante do dia. Ocorreu a atuação do Complexo Convectivo de Mesoescala (CCM). O ar frio e seco com ventos de oeste, sendo este na média troposfera e a advecção do ar quente e úmido na baixa troposfera, juntos, proporcionaram condições para a ocorrência de convecção profunda (EICHHOLZ \& CAMPOS, s/d). Os ventos variaram de 1,2 a $4,9 \mathrm{~m} / \mathrm{s}$ sendo predominantes de SE. A pressão ficou em torno de 970 a 
974 hpa. A média da temperatura ficou em $19,6^{\circ} \mathrm{C}$, sendo a máxima de $26,8^{\circ} \mathrm{C}$ e a mínima de $14,4^{\circ} \mathrm{C}$.

Nos dias 6, 7, 8 e 9 não houve precipitação. Verificou-se a atuação da massa Tropical atlântica (mTa). O aumento da temperatura, a gradativa queda da umidade relativa do ar e um ligeiro declínio da pressão atmosférica foram elementos que contribuíram para essa constatação. Os ventos variaram de $0,0 \mathrm{~m} / \mathrm{s}$ a 1,0m/s. A pressão atmosférica variou de $969,4 \mathrm{hPa}$ a $973,7 \mathrm{hPa}$. As rajadas de vento variaram de $0 \mathrm{~m} / \mathrm{s}$ a $3,3 \mathrm{~m} / \mathrm{s}$. Nesses quatro dias a temperatura mínima foi $10^{\circ} \mathrm{C}$ e a máxima de $29,2^{\circ} \mathrm{C}$. A direção predominante do vento foi de SE.

Nos dias 10 e 11 precipitaram $9 \mathrm{~mm}$ e 40,32mm, respectivamente. A chuva do dia 10 explicada pela presença de uma frente fria, porém, associada à presença dos JST (Jatos Subtropicais) e JPN (Jatos Polares) e a forte divisão em altitude provocou chuvas fortes no sul do Mato Grosso do Sul, Centro-Oeste do Paraná, Santa Catarina e parte do território paulista (Boletim Climanálise, Julho/2009). Por mais que tenha ocorrido o enfraquecimento deste último sistema frontal, verificou-se uma extensa área de baixa pressão em superfície entre o norte da região Sul, Mato Grosso do Sul e São Paulo. Associou-se a este fato, o deslocamento de um intenso cavado, possibilitando a frontogênese, que atuou até dia $13 / 7$ (Boletim Climanálise, Julho/2009). Os ventos foram predominantes de $\mathrm{S}$, variando de $0,0 \mathrm{~m} / \mathrm{s}$ a $8,0 \mathrm{~m} / \mathrm{s}$.

Após esse episódio de chuvas, observou-se onze dias sem a ocorrência de precipitação.

Nos dias 12 e 13 atuou a massa Polar atlântica $(\mathrm{mPa})$. Houve o declínio das temperaturas, sendo a mínima de $3,6^{\circ} \mathrm{C}$ no dia 13 . Os ventos chegaram à velocidade de $0,3 \mathrm{~m} / \mathrm{s}$ às $9 \mathrm{~h}$. A umidade relativa do ar nesse horário estava em $72 \%$. A pressão sofreu ligeiro aumento e ocorreu grande amplitude térmica, sendo que no dia 12 foi de $14,3^{\circ} \mathrm{C}$ e no dia 13 de $20,5^{\circ} \mathrm{C}$.

Nos dias 14, 15 e 16 ocorreu a atuação da massa Polar continentalizada (mPc). As temperaturas sofreram pequenas elevações, sendo que a mínima foi de $9,4^{\circ} \mathrm{C}$ e a máxima foi de $27,8^{\circ} \mathrm{C}$. A umidade manteve-se em torno de $70 \%$. A velocidade do vento oscilou entre $0,0 \mathrm{~m} / \mathrm{s}$ a $5,2 \mathrm{~m} / \mathrm{s}$. Houve declínio da pressão atmosférica.

Entre os dias 17, 18, 19, 20, 21 e 22 atuou a massa Tropical atlântica (mTa). A atuação desse sistema possibilitou a estabilidade do tempo no inverno, devido à subsidência superior nesta célula de alta pressão e ao resfriamento basal da massa de ar. As temperaturas médias variaram de $18,3^{\circ} \mathrm{C}$ a $23,1^{\circ} \mathrm{C}$. Os ventos foram predominantemente de $\mathrm{S}, \mathrm{SE}$ e $\mathrm{N}$ e oscilaram de $0,0 \mathrm{~m} / \mathrm{s}$ a $2,6 \mathrm{~m} / \mathrm{s}$. A umidade relativa do ar, de maneira geral, variou de 40\% a 70\%. A pressão atmosférica alternou de $966,1 \mathrm{hPa}$ a $973,9 \mathrm{hPa}$.

As precipitações verificadas entre os dias 23, 24, 25, 26 e 27, foram provocadas pela atuação do sétimo sistema frontal sobre o continente. Este sistema foi consequência da propagação de um intenso cavado que veio do Pacífico, com a contribuição do sexto sistema frontal que chegou ao extremo sul do continente e atingiu Bahia Blanca na tarde 
do dia 21 (Boletim Climanálise, Julho/2009). Os ventos variaram de $0,0 \mathrm{~m} / \mathrm{s}$ a $3,0 \mathrm{~m} / \mathrm{s}$ e as rajadas chegaram a $5,4 \mathrm{~m} / \mathrm{s}$, durante esse período. As temperaturas diminuíram, sendo a mínima verificada no dia $25, \operatorname{com} 11,2^{\circ} \mathrm{C}$. A umidade relativa do ar aumentou. A precipitação atingiu o índice máximo de $48 \mathrm{~mm}$ no dia 23 e o mínimo ocorreu no dia $27 \mathrm{com}$ 1,66mm. A pressão atmosférica oscilou de 973,0hPa a 974,7hPa. As baixas temperaturas verificadas no continente contribuíram para a atuação prolongada desse sistema. Em se tratando de instabilidade, esse sistema assegurou grandes índices de chuva entre os dias 23 e 24 . A partir do dia 25 esse sistema começou a enfraquecer. Do dia 25 ao 27 observou-se a atuação da massa Polar atlântica $(\mathrm{mPa})$.

No dia 28 ocorreu a atuação da Massa Polar continentalizada (mPc). As temperaturas estiveram em ascensão, a umidade relativa do ar diminuiu e a pressão atmosférica sofreu ligeiro declínio. A velocidade do vento atingiu seu maior índice no dia 24 , chegando á $3,0 \mathrm{~m} / \mathrm{s}$ e a rajada mais forte foi identificada no dia 24 , atingindo o valor de $5,4 \mathrm{~m} / \mathrm{s}$. A amplitude térmica foi de $11^{\circ} \mathrm{C}$. Não houve precipitação.

A chuva verificada no dia 29 deveu-se a atuação de uma frente fria que se formou à leste e sul do Brasil. Porém, sua maior atuação foi na região leste do estado, provocando granizo na capital (Boletim Climanálise, Julho/2009). A pressão atmosférica variou de $968,7 \mathrm{hPa}$ a $972,1 \mathrm{hPa}$. A temperatura mínima foi $17,8^{\circ} \mathrm{C}$ e a máxima de $25,8^{\circ} \mathrm{C}$. Os ventos chegaram a $3,1 \mathrm{~m} / \mathrm{s}$. A taxa de umidade subiu.

Entre os dias 30, 31 de julho e 1 de agosto constatou-se a atuação da massa Polar. Os ventos do quadrante $\mathrm{L} / \mathrm{SE}$, a estabilidade do tempo, a pressão atmosférica com índices altos, em torno de $974,6 \mathrm{hPa}$, as temperaturas na média de $19,7^{\circ} \mathrm{C}$, sendo a mínima de $12,4^{\circ} \mathrm{C}$ e a máxima de $27^{\circ} \mathrm{C}$, são elementos que levam a essa afirmação.

Nos dias 2 e 3 verificou-se a atuação de uma frente fria. Em ambos os dias o total de precipitação foi $1,66 \mathrm{~mm}$. Às $14 \mathrm{~h}$ do dia 2 observou-se a velocidade do vento em torno de $5,2 \mathrm{~m} / \mathrm{s}$ e as rajadas chegando em $10,9 \mathrm{~m} / \mathrm{s}$. A temperatura mínima foi de $15,5^{\circ} \mathrm{C}$ e a máxima atingindo o valor de $25,4^{\circ} \mathrm{C}$. A pressão atmosférica variou de $968,3 \mathrm{hPa}$ a $974,3 \mathrm{hPa}$.

No período de 4 a 7 de agosto verificou-se ausência de precipitação, e o tempo caracterizado como estável. Constatou-se a atuação da massa Polar (enfraquecida). Noto-use o aumento da temperatura, queda da umidade relativa do ar, ligeiro declínio da pressão atmosférica. Em todos esses dias, os ventos não passaram de $5,5 \mathrm{~m} / \mathrm{s}$. Baixa nebulosidade. Nesses quatro dias a temperatura mínima foi de $10,7^{\circ} \mathrm{C}$ no dia 4 e a máxima de $32,8^{\circ} \mathrm{C}$ no dia 7 . A direção predominante do vento foi de $\mathrm{O}, \mathrm{S}, \mathrm{N}$ e $\mathrm{SE}$, respectivamente.

No período de julho e primeira semana de agosto de 2009 foram registradas anomalias positivas de precipitação $(183,92 \mathrm{~mm})$, sendo o mês mais chuvoso quando se compara com a série histórico-climatológica utilizada (Bieras, 2006). Em contrapartida, a temperatura enquadra-se no que se considera habitual para o período $\left(18,6^{\circ} \mathrm{C}\right)$.

A Figura 3 caracteriza os elementos climáticos e os sistemas atmosféricos atuantes na região durante o período de julho e primeira semana de agosto de 2009. 


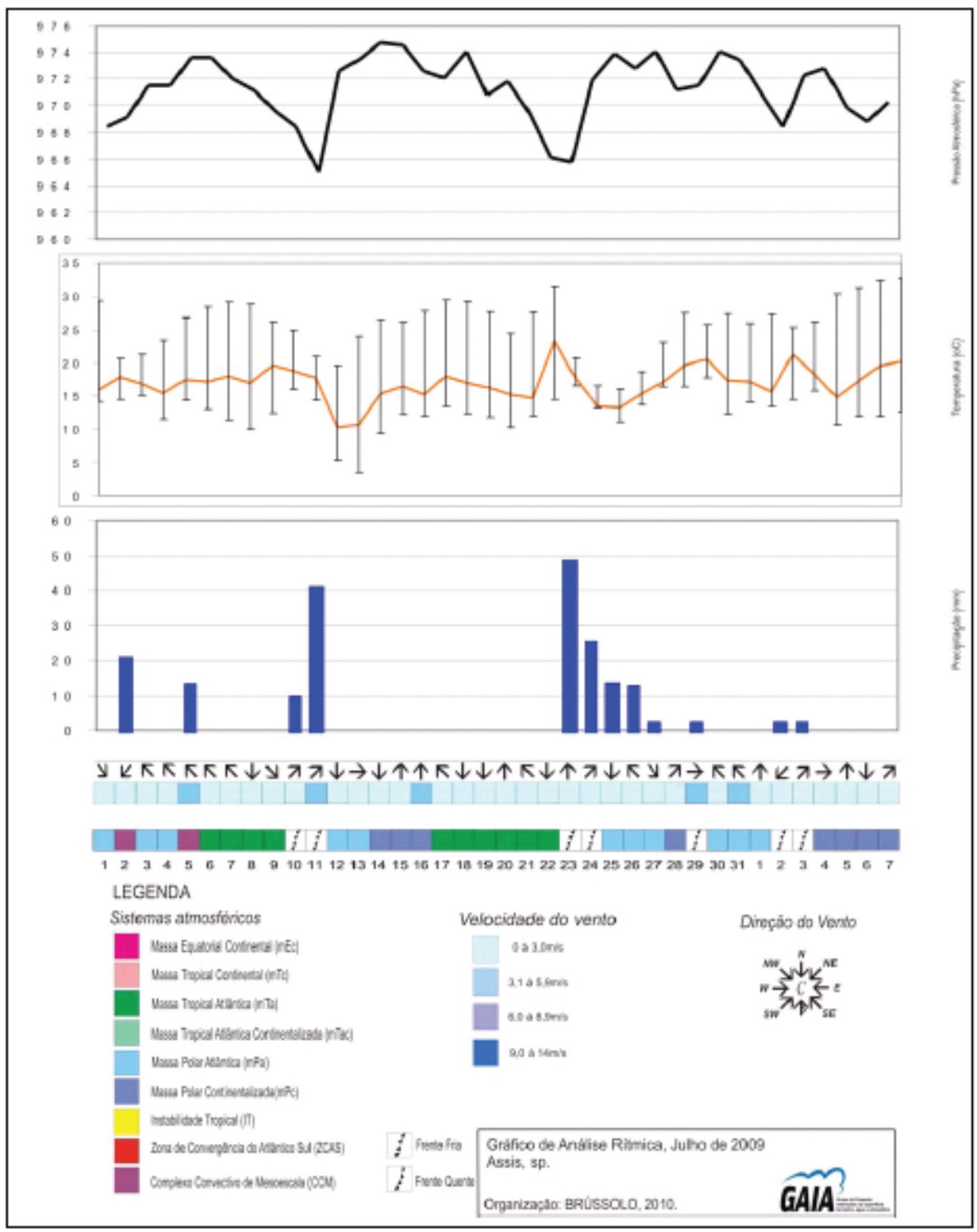

Figura 3. Variação dos elementos climáticos e sistemas atmosféricos atuantes em Assis-Julho/ Agosto de 2009.

Fonte: Dados da Pesquisa, 2009.

A elaboração desse gráfico de análise rítmica contribui para o entendimento sistêmico do clima urbano, fornecendo possibilidades de análise dos sistemas atmosféricos atuantes na região de Assis durante a coleta de dados. 
Para essa apresentação serão demonstrados apenas os horários das 18:00 e 00:00 (Horário de Brasília), com o intuito de demonstrar o comportamento da temperatura e umidade relativa do ar nos pontos de coleta de dados.

O ponto Rural foi o local que apresentou a menor temperatura, com exceção do dia 22, em que o Rural estava mais quente que o ponto Periferia e Centro. Mas não deixando também de haver exceções quanto ao comportamento térmico apresentado nestes episódios.

Cabe salientar que os dados seriam coletados somente no mês de julho, somando 31 dias de coleta, porém problemas com as miniestações impossibilitaram os registros de alguns dias do mês de julho, sendo assim foi expandida a coleta dos dados para a primeira semana de agosto, somando 38 dias.

A Figura 4 ilustra a variação da temperatura nos três pontos de coleta dos dados: "Periferia, Centro e Rural", durante o mês de julho e os seis primeiros dias de agosto de 2009 no período das 18:00.

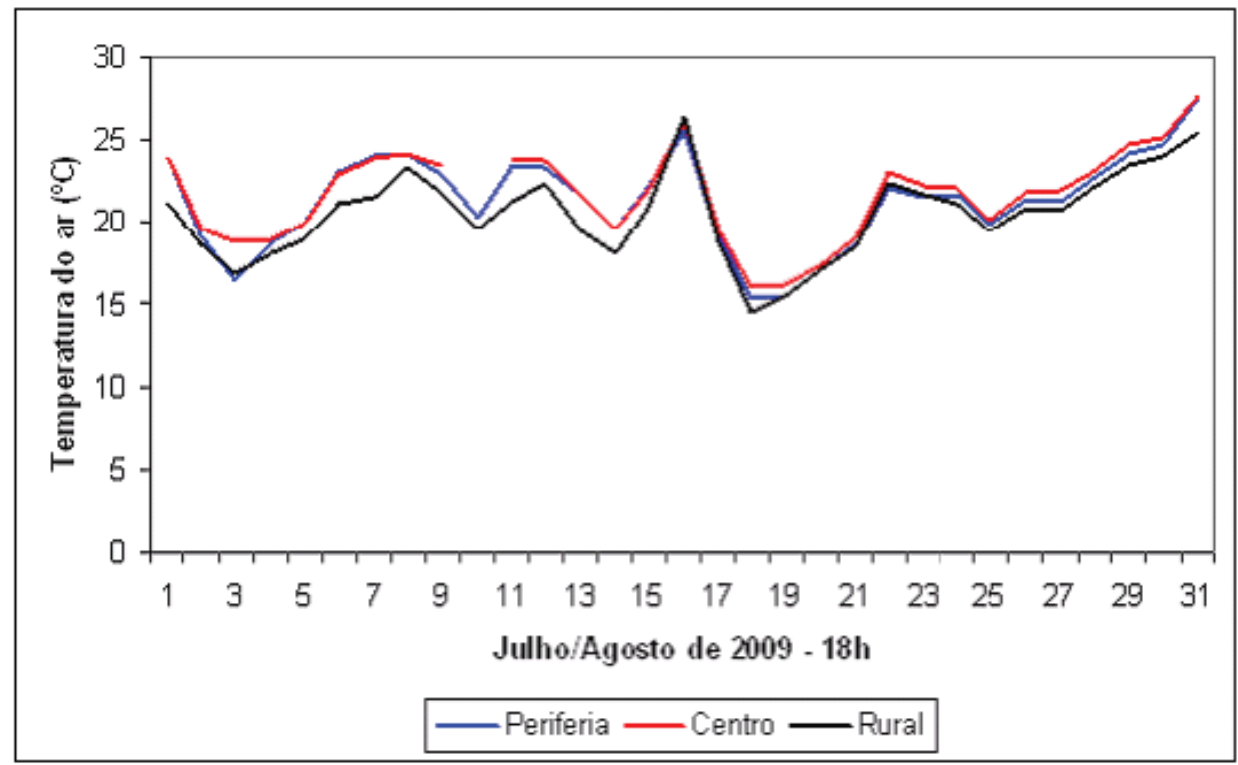

Figura 4. Variação da temperatura nos três pontos de coleta de dados: Periferia, Centro e Rural às 18:00.

Fonte: Dados da pesquisa, 2009.

A Figura 5 fornece a variação da umidade relativa do ar nos três pontos de coleta dos dados: "Periferia, Centro e Rural", durante o mês de julho e os seis primeiros dias de agosto de 2009 no período das 18:00. 


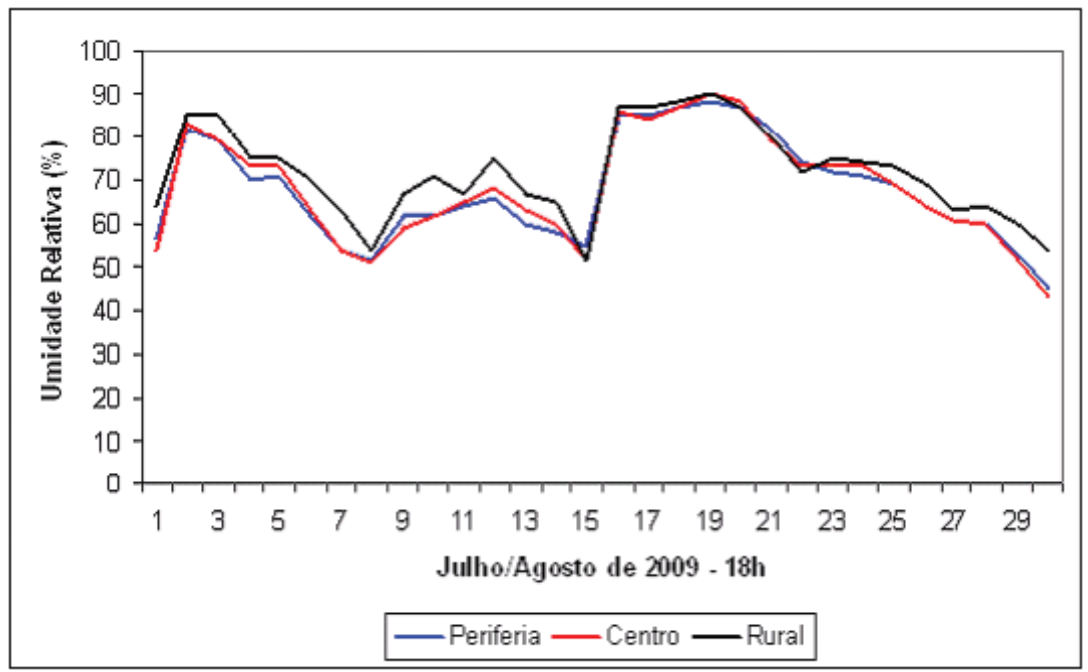

Figura 5. Variação da umidade relativa do ar nos três pontos de coleta de dados: Periferia, Centro e Rural ás 18:00. Fonte: Dados da pesquisa, 2009.

A Figura 6 demonstra a variação da temperatura nos três pontos de coleta dos dados: "Periferia, Centro e Rural", durante o mês de julho e os seis primeiros dias de agosto de 2009 no período das 00:00.

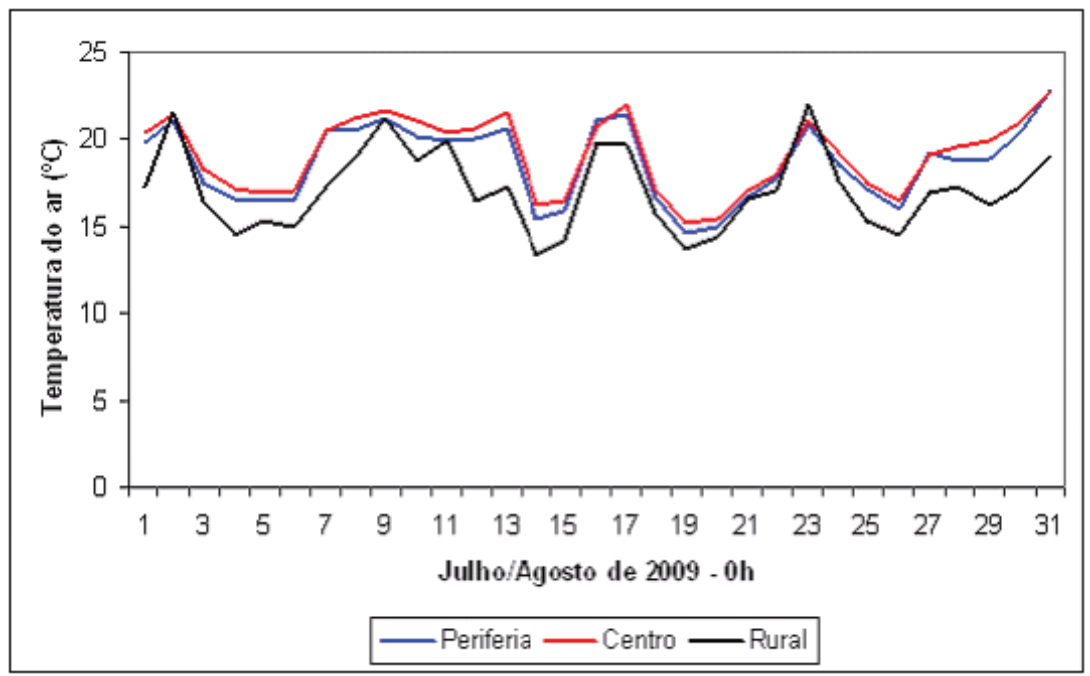

Figura 6. Variação da temperatura nos três pontos de coleta de dados:

Periferia, Centro e Rural às 00:00.

Fonte: Dados da pesquisa, 2009. 
A Figura 7 evidencia a variação da umidade relativa do ar nos três pontos de coleta dos dados: "Periferia, Centro e Rural", durante o mês de julho e os seis primeiros dias de agosto de 2009 no período das 00:00.

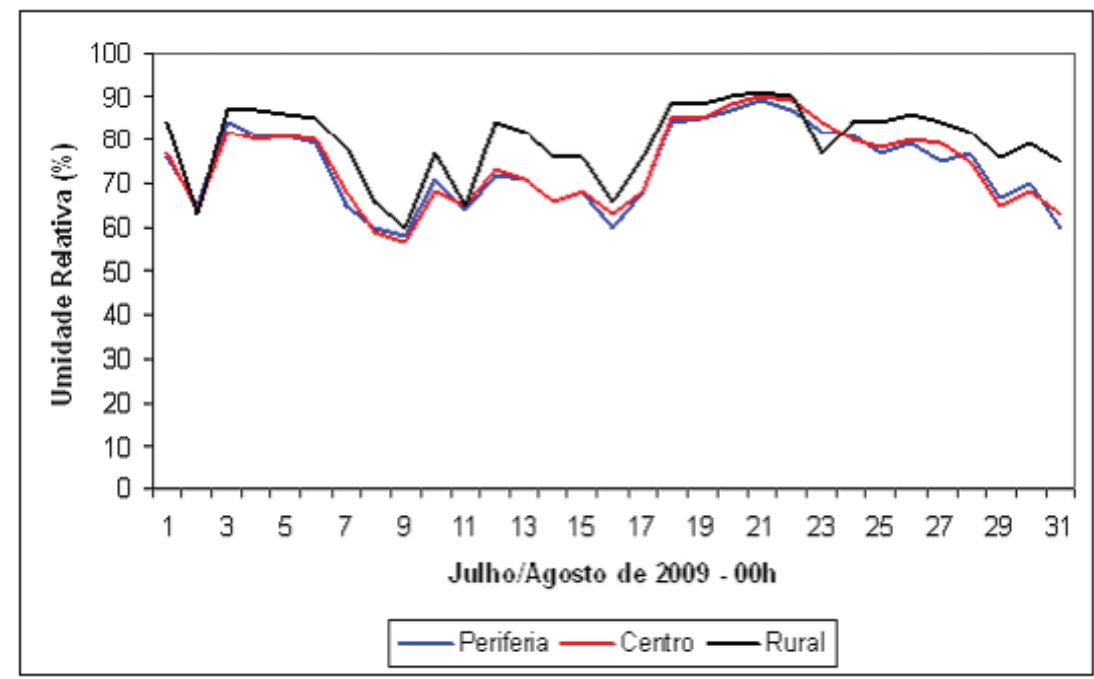

Figura 7. Variação da umidade relativa do ar nos três pontos de coleta de dados:

Periferia, Centro e Rural às 00:00.

Fonte: Dados da pesquisa, 2009.

A análise dos dados de temperatura e umidade relativa do ar fornece condições para compreender e diagnosticar as diferenças que o ambiente urbano pode proporcionar aos elementos climáticos citados acima.

\section{Considerações finais}

Constatou-se que julho de 2009 foi considerado um mês chuvoso em relação à normal climatológica para o período. Porém, foi diagnosticado diferenças termohigrométricas entre os pontos de coleta Periferia, Centro e Rural. Em grande parte do período de análise (julho e primeira semana de agosto de 2009), o ponto Centro apresentou maiores temperaturas e menores taxas de umidade. $\mathrm{O}$ ponto Rural caracterizou-se por menores temperaturas e maiores taxas de umidade. Em alguns dias e horários o ponto representativo do rural, apresentou temperaturas mais elevadas do que os outros pontos. Este fato precisa ser melhor investigado para se buscar uma explicação para tais ocorrências. Com os dados obtidos e as metodologias adotadas, não é possível aprofundar na discussão desses dados, todavia, atinge os objetivos propostos para a pesquisa inicial.

O ponto Periferia identificou-se como intermediário. Essas diferenças ocorreram em consequência do ponto denominado Centro estar localizado numa área densamente ocupada, com fluxo constante de veículos etc. O ponto Rural apresentou-se com 
menores temperaturas e maiores taxas de umidade, devido à diferenciação dos padrões de ocupação do ponto Centro. Já o ponto Periferia caracterizou-se como intermediário, devido à menor densidade de construções, maiores áreas verdes, baixo fluxo de veículos etc.

As diferenças espaciais dos elementos climáticos (temperatura e umidade relativa) referem-se, em grande parte, pelo uso e ocupação do solo diferenciados. A impermeabilização do solo, o crescimento/adensamento de materiais antropogênicos, a retirada da cobertura vegetal, a canalização de corpos d'agua, são fatores que contribuem para o aumento da temperatura e diminuição da umidade relativa do ar. Todavia, outros fatores fornecem condições para o aparecimento de um clima urbano específico, como, a exposição das vertentes, as características climáticas da região, a altitude, a presença de corpos d'agua e de vegetação ou não nas proximidades, etc.

É notório que o clima exerce grande influência na vida dos seres humanos, pois propicia condições favoráveis ou desfavoráveis para o conforto térmico.

Para a melhoria do conforto térmico, e consequentemente, para o bem-estar da população, são necessárias algumas mudanças em relação à estrutura e funcionalidade urbana.

Tendo isso como base, verificou-se que Assis possui um clima urbano específico, sendo necessárias políticas voltadas ao planejamento urbano, visando a melhoria da qualidade ambiental urbana. Primeiramente é preciso a regulamentação do uso e ocupação do solo urbano, visando o conforto térmico coletivo. Concomitantemente, é necessário o desenvolvimento de pesquisas para a produção de materiais de construção para telhados, paredes, janelas etc., que sejam adaptados às condições tropicais e de menor custo.

\section{Referências}

AMORIM, M. C. C. T. O clima urbano de Presidente Prudente/SP. 2000. 374p. p.01-80. Tese (Doutorado em Geografia) - Faculdade de Filosofia, Letras e Ciências Humanas, Universidade de São Paulo. São Paulo.

; Caracterização das áreas verdes em Presidente Prudente. In: SPOSITO, M. E. B. (org.). Textos e contextos para a leitura geográfica de uma cidade média. Presidente Prudente: [s.n.], 2001.

ANUNCIAÇÃO, V. S. O clima urbano de Campo Grande, MS. 2001. Dissertação (Mestrado em Geografia) - Faculdade de Ciências e Tecnologia, Universidade Estadual Paulista, Presidente Prudente.

ARAÚJO, R. R. O processo de urbanização na produção do clima urbano de São LuísMA. 2001. 216p. p. 05-25. Dissertação (Mestrado em Geografia) - Faculdade de Ciência e Tecnologia, Universidade Estadual Paulista, Presidente Prudente.

AYOADE, J. O. Introdução à climatologia para os trópicos. Rio de Janeiro: Bertrand Brasil, 2007. 332p. 
BARRIOS, N. A. Z.; SANT’ANNA NETO, J. L. A circulação atmosférica no Extremo Oeste Paulista. In: Boletim Climatológico. Presidente Prudente, 1996. (p. 07-14).

BEREZUK, A. Análise das adversidades climáticas no oeste paulista e norte do Paraná. 2007, 362p. p. 60-80. Tese (Doutorado em Geografia) - Faculdade de Ciências e Tecnologia, Universidade Estadual Paulista, Presidente Prudente.

BIERAS, A. R. Variabilidade e tendência climática e a produtividade da soja no Estado de São Paulo. 2006. p. 63-111. Tese (Doutorado em Geografia) - Instituto de Geociências e Ciências Exatas, Universidade Estadual Paulista, Rio Claro.

BOIN, M. N. Chuvas e Erosões no Oeste paulista: uma análise climatológica aplicada. 2000. 264p. p. 14-55. Tese (Doutorado em Geociências e meio ambiente) - Instituto de Geociências e Ciências Exatas, Universidade Estadual Paulista, Rio Claro.

BRANDÃO, A. M. de. P. M. O Clima Urbano da Cidade do Rio de Janeiro. 1996. p.85. Tese (Doutorado em Geografia) - Faculdade de Filosofia, Letras e Ciências Humanas, Universidade de São Paulo, São Paulo.

; O clima urbano da cidade do Rio de Janeiro. Clima urbano. Org. Mendonça, F. Monteiro, C. A. de F. São Paulo: Contexto, p.122, 2003.

CHANDLER, T. J. The climate of London. London: Hutchison of London, 1965. 287p.

CRUZ, J. C. L. Características térmicas da camada intra-urbana me Rio Claro (SP). 1995. Dissertação (Mestrado em Geografia) - Instituto de Geociências e Ciências Exatas, Universidade Estadual Paulista, Rio Claro.

DANNI, I. M. A ilha de calor de Porto Alegre: contribuição ao estudo do clima urbano. Boletim Gaúcho de Geografia, Porto Alegre, n. 8, maio. 1987.

FIALHO, E.S. Ilha de calor em cidade de pequeno porte: Caso de Viçosa, na Zona da Mata Mineira. São Paulo. Tese (Doutorado em Geografia) - Faculdade de Filosofia, Letras e Ciências Humanas, Universidade de São Paulo, São Paulo.

FONZAR, B.C. O processo de ocupação regional, o modelo urbano e o conforto térmico na Alta Sorocabana: um teste aplicado a Presidente Prudente. Rio de Janeiro. Revista Brasileira de Geografia, n.4, 1986.

FORSDYKE, A. G. Previsão do tempo e clima. São Paulo: Melhoramentos, 1978.

GARCÍA, F. F. Manual de climatologia aplicada: clima, médio ambiente y planificácion. Madrid: Editorial Sítesis, S. A., 1996. 285p.

GONÇALVES, N. M. S. Impactos pluviais e desorganização do espaço urbano em Salvador. São Paulo, 1992. Tese (Doutorado em Geografia) - Faculdade de Filosofia, Letras e Ciências Humanas, Universidade de São Paulo, São Paulo.

JAUREGUI, E. The urban climate of México City. Erdkund. In: Ban XXXVII, Helf 4, 1973.

LANDSBERG, M. E. The urban climate. New York: Academia Press, 1981. 276p. 
LIMA, G.N. de. Características do clima urbano de Nova Andradina/MS. Presidente Prudente, 2011. Dissertação (Mestrad em Geografia) - Faculdade de Ciências e Tecnologia, Universidade Estadual Paulista, Presidente Prudente.

LOMBARDO, M. A. Ilha de calor nas metrópoles: o exemplo de São Paulo. São Paulo: Hucitec, 1985. 244p.

LOWRY, W,P. Empirical estimation of urban effects on climate: a problem analysis. Journal of apllied meteorogy. Journal of Applied Meteorology, vol 16, nº 2, 1977.

MACHADO, J. C dos S. Dimensões do processo histórico de desenvolvimento econômico do primeiro cinqüentenário do município de Assis: 1905-1955. São Paulo: Autor, 2005. $221 \mathrm{p}$.

MAITELLI, G. T. Uma abordagem tridimensional de clima urbano em área tropical continental: o exemplo de Cuiabá/MT. 1994. Tese (Doutorado em Geografia) Departamento de Geografia, Faculdade de Filosofia, Letras e Ciências Humanas, Universidade de São Paulo, São Paulo.

MENDONÇA, F. de A. O clima e o planejamento urbano de cidade de porte médio e pequeno: proposição metodológica para estudo e aplicação à cidade de Londrina, PR. 1994. 322p. Tese (Doutorado em Geografia Física) - Faculdade de Filosofia, Letras e Ciências Humanas, Universidade de São Paulo, São Paulo.

MENDONÇA, F. MONTEIRO, C. A. de F. Clima urbano. São Paulo: Contexto, 2003, p 96.

MENDONÇA, F. DANNI-OLIVEIRA, I. M. Climatologia: noções básicas e climas do Brasil. Oficina de textos. 2007, p 92.

MONTEIRO, Ana. O clima urbano do Porto: contribuição para a definição das estratégias de planejamento e ordenamento do território. Fundação Calouste Gulbenkian, Junta Nacional de Investigação Cintifica e Tecnológica, 1997. 485p.

MONTEIRO, C. A. de F. Análise rítmica em climatologia: problemas da atualidade climática em São Paulo e achegas para um programa de trabalho. Climatologia. São Paulo. n.1. p 1-20, 1971.

; O clima e a organização do espaço no Estado de São Paulo: Problemas e Perspectivas. São Paulo: IGEOG/USP, 1971.

; Fluxos polares e as chuvas de primavera-verão no estado de são Paulo: uma análise quantitativa do processo genético. São Paulo: Instituto de Geografia/ Universidade de São Paulo, 1975.

; Teoria e clima urbano. São Paulo: IGEOG/USP, 1976. 181p. (Séries Teses e Monografias, 25).

; Por um suporte teórico e prático para estimular estudos geográficos do clima urbano no Brasil. Geosul, Florianópolis, v.5, n.9, 1990.

$\overline{\mathrm{n} .9,1990}$

; Adentrar a cidade para tomar-lhe a temperatura. Geosul, Florianópolis, v.5, 
; Clima e Excepcionalismo: Conjecturas sobre o desempenho da atmosfera como fenômeno geográfico. Editora UFSC, 1991. 233p. p. 10-25.

OKE, T. R. The distinction between canopy and boundary-layer heat islands. Atmosphere $14,1976$.

; Boundary Layer Climates. London: Methuem \& Ltd. A.Halsted Press Book, John Wiley \& Sons, New York, 1978, 372p.

PEDELABORDE, P. Introduction a l'étude scientifi que du climat. Paris: Centre de Documentation Cartographique, 1959.

PITTON, S. E. C. As cidades como indicadores de alterações térmicas. 1997. 272p. p. 04-31. Tese (Doutorado em Geografia Física) - Faculdade de Filosofia, Letras e Ciências Humanas, Universidade de São Paulo, São Paulo.

SAMPAIO, Antonio Heliodoro L. Correlações entre uso do solo e ilha de calor no ambiente urbano: $O$ caso de Salvador. 1981. Dissertacão (Mestrado em Geografia Humana) - Faculdade de Filosofia, Letras e Ciências Humanas, Universidade de São Paulo, São Paulo.

SANT'ANNA NETTO, J. L. As chuvas no Estado de São Paulo. 1995. p 30, 63-78. Tese (Doutorado em Geografia) - Faculdade de Filosofia, Letras e Ciências Humanas, Universidade de São Paulo, São Paulo.

; (org) Os climas das cidades brasileiras. Presidente Prudente: UNESP, 2002. $227 \mathrm{p}$.

; TOMMASELLI, J.T.G. O tempo e o clima de Presidente Prudente, 2009.

SARTORI, M. G. B. O clima de Santa Maria: do regional ao urbano. 1979. $163 f$. Dissertação (Mestrado em Geografia) - Faculdade de Filosofia, Letras e Ciências Humanas, Universidade de São Paulo, São Paulo.

SECCHI, C. E.; MENOTTI, S. S. A cidade e o campo: estudo comparativo das variações térmicas e higrométricas em Presidente Prudente/SP. 2002. Monografia (para obtenção do Título de Bacharel em Geografia) - Faculdade de Ciências e Tecnologia, Universidade Estadual Paulista, Presidente Prudente.

SECCHI CAMARGO. E. Qualidade AmbientaL Urbana em Presidente Prudente. 2007. 152p. Dissertação (Mestrado em Geografia) - Faculdade de Ciências e Tecnologia, Universidade Estadual Paulista, Presidente Prudente.

SETTE, D.M. O clima urbano de Rondonópolis-MT. 1996. 137p. Dissertação (Mestrado em Geografia Física) - Faculdade de Filosofia, Letras e Ciências Humanas, Universidade de São Paulo, São Paulo.

SILVA, L.F. Estudo do campo térmico da cidade de São Carlos (SP) em um episódio climático de inverno. 2011. Tese (Doutorado em Ciências da Engenharia Ambiental) Universidade de São Paulo, São Carlos. 
SORRE, M. Adaptação ao Meio Climático e Biossocial : geografia psicológica (1951). In: MEGALE, J. F. (org.) Max Sorre: geografia. São Paulo: Ática, 1984, p.30 - 86. (Série Grandes Cientistas Sociais).

SORRE, M. Fundamentos biológicos de la geografía humana: ensayos de una ecología del hombre. Barnacelona. Juventd, 1955. 344p.

SOUZA, J. L. de. Análise do campo Térmico de Cidades de Médio Porte: Estudo de caso no Pólo Têxtil de Americana-SP. 2007. p.30-48. Dissertação (Mestrado em Geociências e meio ambiente) - Instituto de Geociências e Ciências Exatas, Universidade Estadual Paulista, Rio Claro.

TARIFA, J. R. Fluxos polares e as chuvas de primavera-verão no Estado de São Paulo. 1975. Universidade de São Paulo, 1975. 93p. (Séries Teses e Monografias 19).

. Análise comparativa da temperatura e umidade na área urbana e rural de São José dos Campos (SP). Geografia, v.2, n.4, outubro 1977.

TAVARES, A.C. O clima local de Campinas. 1974. Dissertação (Mestrado em Geografia Física) - Faculdade de Filosofia, Letras e Ciências Humanas, Universidade de São Paulo, São Paulo.

TOMÁS, D. D. Comportamento da umidade relativa do ar em centros urbanos: o exemplo da metrópole de São Paulo. 1999. Dissertação (Mestrado em Geografia Física) - Faculdade de Filosofia, Letras e Ciências Humanas, Universidade de São Paulo, São Paulo.

VECCHIA, F. Clima e ambiente construido: a abordagem dinâmica aplicada ao Conforto Térmico. 1997. Tese (Doutorado em Geografia Física) - Faculdade de Filosofia, Letras e Ciências Humanas, Universidade de São Paulo, São Paulo.

VIANA, S. S. M. Caracterização do clima urbano em Teodoro Sampaio. 2006. Dissertação (Mestrado em Geografia) - Faculdade de Ciências e Tecnologia, Universidade Estadual Paulista, Presidente Prudente.

ZAMPARONI, C. A. P. G. Ilha de Calor em Barra do Bugres e Tangará da Serra - MT: Uma Contribuição ao Estudo do Clima Urbano em Cidades de Pequeno Porte em Área Tropical. 1995. Dissertação (Mestrado em Geografia Física) - Faculdade de Filosofia, Letras e Ciências Humanas, Universidade de São Paulo, São Paulo.

ZAVATTINI, J. A. Estudos do clima no Brasil. Campinas: Alínea, 2004.

\section{Agradecimentos}

À Universidade Estadual Paulista, campus de Presidente Prudente e ao Fundo de Amparo a Pesquisa do Estado de São Paulo (FAPESP) pelo apoio financeiro. 


\section{RAFAEL GOTARDi BRÚSSOLO}

Licenciado e Bacharel em Geografia pela Unesp, campus de Presidente Prudente. Mestre em Geografia pela Universidade Estadual de Londrina. Atualmente é doutorando em Ciências da Engenharia Ambiental pela Escola de Engenharia de São Carlos, Universidade de São Paulo.

Universidade de São Paulo - Campus de São Carlos Av. Trabalhador São-carlense, 400, Arnold Schimidt

São Carlos - São Paulo - Brasil - CEP 13566-590

Email: rgbrussolo@usp.br

Recebido para publicação em agosto de 2015 Aprovado para publicação em dezembro de 2016 